\title{
Chemical reactions at high-speed HFC-boriding
}

\author{
Alexander Katasonov ${ }^{1, *}$, Vladimir Malikov ${ }^{l}$, and Alexey Ishkov $^{2}$ \\ ${ }^{1}$ Altai State University, Lenina str., 61, Barnaul, 656049, Russia \\ ${ }^{2}$ Altay State Agricultural University, Krasnoarmejskij str., 98, Barnaul656049, Russia
}

\begin{abstract}
Strengthening of parts and units of machines, increased reliability and longer service life is an important task of modern industry. As an promising materials for protective-strengthening coatings, offered matrix composites based on the ternary system $\mathrm{Fe}-\mathrm{B}-\mathrm{Fe}_{\mathrm{n}} \mathrm{B}$. The article is proposed the complex heating of steel being borated and imbued medium by high frequency currents (HFC), and to combine the diffusion boriding from liquid and solid media and the transition of the diffusion boriding to chemical interaction between the elements of $\mathrm{Fe}$ and $\mathrm{B}$. We determined the main components of the reaction-boronizing system, as well as their roles and possible processes that lead to the implementation of topochemical boriding initiated by HFC-heating. Confirmed the course of the reaction leading to the occurrence of reducing agents $\mathrm{Ca}, \mathrm{Si}$ and active boron in the boronizing mixture.
\end{abstract}

\section{Introduction}

It is well established that nitrocarburising and boriding treatment of steels generate surfaces which causes considerable modification in the mechanical, tribological and corrosion properties $[1,2]$.

In boronizing process, diffusion of boron into the steel surface leads to the formation of boride layer, which includes either a single-phase layer of $\mathrm{Fe} 2 \mathrm{~B}$ or two-phase layer of Fe2B and $\mathrm{FeB}[3-6]$.

Boride layers formed on the diffusion boriding steel parts considerably (5-30 fold) increase the abrasion resistance, heat resistance (1.5 - 2 fold) and corrosion resistance, which improves the life of the hardened product [7].

After the "classic" boriding, the coating microstructure, most often, is coalescent at the bottom of boride needles, that form a coating layer. Resulting internal tensile stresses in the borated coating significantly reduce their plasticity, therefore peeling and chipping of such a hardening coating occur, until its complete destruction, at relatively small bending, shock or compressive stresses and especially reversed loads and vibrations.

All of the aforesaid restrains application of isothermal boriding process for wide use when hardening parts surfaces made of steel in agricultural machinery industry.

\footnotetext{
*Corresponding author: mirotnas@gmail.com
} 
Boriding, is a thermochemical surface treatment, in which boron is diffused into, and combines with the substrate material forming a single or double-phase metal boride layer at the surface. The boriding of ferrous materials causes the formation of either a single layer (Fe2B) or double-layer $(\mathrm{FeB} / \mathrm{Fe} 2 \mathrm{~B})$ with definite composition. The thickness of the layer formed (which is known as the case depth), has an effect on the mechanical and chemical behaviors of the borided steels, that depends on the boriding temperature, the treatment time and the boron potential that surrounds the sample surface [8]. When the treatment time, and temperature are increased, the FeB regions become much deeper, and they grow from compact and oriented Fe2B crystals. The phases grow preferentially in the (002) plane, increasing the mechanical stress over the $\mathrm{FeB} / \mathrm{Fe} 2 \mathrm{~B}$ interface because of the significant differences between the expansion coefficients of both phases in the range of 473 to $873 \mathrm{~K}$.

The surface hardness of the boride layers is usually measured by traditional techniques such as the Knoop and Vickers microhardness. However, as a result of its wide acceptance for exploring the mechanical behavior of elastic-plastic materials, such as ceramics, the nanoindentation technique has also been used to measure different mechanical properties under monotonic loading and unloading, in which the data are usually processed by the manner proposed by Oliver and Pharr [9]. Some devices also enable continuous stiffness measurement (so-called CSM mode), where a small harmonic signal (amplitude of several nmor a fraction of amN) is added to the monotonously increasing basic load. The harmonic contact stiffness is measured continuously, andmakes possible the determination of properties during loading from "zero" to the maximum force. However, the CSM mode is especially suitable for materials with time-dependent response, such as plastics or biomaterials $[10,11]$.

In recent years, Culha et al. [12] employed ultra-microhardness tests to estimate the mechanical properties of FeB layers, such as the dynamic hardness and the Young's modulus in AISI 1020 and 1040 borided steels.

The steelswere exposed to different experimental conditions during the boriding process. The load-dependant elastic modulus and the dynamic hardness values of the FeB layer were within the range of 125-397 GPa and 775-1381 HV, respectively. The validity of the Young's modulus values proposed in [13] was verified taking into account that the indentation depth should not exceed $10-25 \%$ of the boride layer thickness, avoiding the effect of the steel properties in the elastic values of the FeB layer. In addition, finite element modeling was applied to simulate the yield strength of the FeB layer on a low-alloy steel substrate; the resultant values ranged from 5 to $7 \mathrm{GPa}$ [13].

The mechanical properties such as fracture toughness, compressive residual stresses, and the indentation size effect (ISE) were also evaluated in the tips of the needles of the $\mathrm{Fe} 2 \mathrm{~B}$ layer using the Berkovich nanoindentation technique [15]; the results showed an apparent hardness of approximately $14 \mathrm{GPa}$ with a fracture toughness between 2.4 and 2.7 $\mathrm{MPa}$, and the compressive residual stresses were between 351 and $471 \mathrm{MP}$

In case of boriding by HFC-heating, the speed of coating formation increases hugely more due to increase of heating rate, if special fluxes are used there is no need to create a protective atmosphere, since the boriding time does not exceed several minutes. Besides HFC-heating allows to reduce time of high temperatures effect on the base material, as well as to combine easily the boriding process with subsequent heat treatment. In the future, little time for boriding carried out by HFC-heating, may promote the use of this boriding method in flow production lines, in mass production, and production of large quantities of hardened parts per shift. 
Previously, the authors developed an original method of strengthening WTs by velocity RF-borating, which allows one to obtain a layer of wear-resistant composite (FenB-Fe-B) boride coating with a thickness of $350-600 \mu \mathrm{m}$ for $1-2 \mathrm{~min}$ on the surface of the steel detail [15].

Considering the fact that HFC-heating allows to heat the steel surface up to 900-1,000 ${ }^{\circ} \mathrm{C}$ [16] within very short periods, there is a real opportunity not only to obtain boride coatings during HFC-heating boriding, but also their phase and structural homogenization, due to remelting under the heat released in the surface layers during HFC-heating, heat of chemical reactions in the boronizing composition and heat of the primary topochemical reaction.

In this work, we determined the main components of the reaction-boronizing system, as well as their roles and possible processes that lead to the implementation of topochemical boriding initiated by HFC-heating.

\section{Materials and Methods}

As an promising materials for protective-strengthening coatings, offered matrix composites based on the ternary system $\mathrm{Fe}-\mathrm{B}-\mathrm{Fe}_{\mathrm{n}} \mathrm{B}$, formed directly on the surface of the reinforcing parts, when it boriding in conditions of induction heating of the charge of the original composition and the various functional fillers.

Coating the ternary system $\mathrm{Fe}-\mathrm{B}-\mathrm{Fe}_{\mathrm{n}} \mathrm{B}$ formed by induction heating on the surface of the reinforcing parts when passing exothermic topochemical reaction between iron steel and boron the charge, the reaction captures the surface layer of the base-material and the reaction products form with it a single whole and characterized by smoothly changing the chemical composition of the transition at the interface base-coat which determines their high adhesion strength and durability, special properties.

Coating samples were obtained for $65 \mathrm{G}$ grade steel made of compositions of boron carbide and amorphous boron under conditions of high-frequency heating to research boriding processes performed together with HFC-heating of surface of structural and alloy steels of main grades used in an agricultural machinery industry, and the effect of carbon and alloying elements in steel, physical, physical and mechanical properties and wear resistance of boride coatings.

Boride coatings of $65 \mathrm{G}$ steel during simultaneous SHS process and HFC-heating were obtained from a modified mixture of $2 \mathrm{Al}+\mathrm{B}_{2} \mathrm{O}_{3}$ composition containing 20 and $30 \%$ of $\mathrm{P}$ 0.66 flux. Temperature of boriding process in all cases was $950-1250^{\circ} \mathrm{C}$, saturation time was 40 - $180 \mathrm{sec}$.

To study the possible chemical reactions that lead to the boronizing of steel surfaces by means of HFC-heating, the following main components of the boronizing compositions were selected:

Boron carbide $\left(\mathrm{B}_{4} \mathrm{C}\right)$ or amorphous boron (Bamorph.) were included as boronizing agents that provide active boron $\left(\mathrm{B}^{*}\right)$ and additional heat due to their thermal dissociation processes, chemical and physicochemical processes using HFC-heating in the air:

Fused flux P-0.66, consisting of borax glass, boron oxide, silicocalcium and welding flux AN-348A in \%wt: $30 \% \mathrm{Na}_{2} \mathrm{~B}_{4} \mathrm{O}_{7}, 20 \% \mathrm{~B}_{2} \mathrm{O}_{3}, 10 \% \mathrm{CaSi}_{2}, 40 \% \mathrm{AH}-348 \mathrm{~A}$ is the main component of the boronizing composition and performs the functions of the transport medium, it melts and changes stage of the HFC-boriding from solid to quasi-liquid, wets and cleans surface of steels from oxides and reaction products, and also has additional boronizing effect and generates ionic forms of boron and its compounds. The main 
component of the P-0.66 flux is an eutectic mixture of $\mathrm{B}_{2} \mathrm{O}_{3}$ and $\mathrm{Na}_{4} \mathrm{~B}_{2} \mathrm{O}_{7}$ with a mass ratio of substances of 0.66 , which melts when heated above 500-520 ${ }^{\circ} \mathrm{C}$, forms complex mixtures of meta- and orthoborates, active boron in cationic ( + ) and anionic (-) forms, reacts with oxides on steel surface and other components of the mixture:

Calcium silicide $\left(\mathrm{CaSi}_{2}\right)$, included into the flux in an amount of up to $10-15 \% \mathrm{wt}$, appears to be strong reducing agent, reactive compound, steel surface deoxidizing agent, and also as a high-temperature fluxer (due to released silicon) and others when starts thermally dissociate at $720-740{ }^{\circ} \mathrm{C}$. Besides, the calcium silicide in fused flux significantly reduces its hygroscopicity, increases the shelf life of ready-to-use boronizing compositions and reduces their splashing during HFC-heating and melting, since it binds quickly the adsorbed and absorbed moisture in $\mathrm{Ca}(\mathrm{OH}) 2$.

Welding flux AN-348, included in P-0.66 up to $100 \%$, is used mainly to improve the wetting of the steel surface, the binding of reaction products and slag removal at high temperatures, when the borax and boric anhydride on the steel surface do not "work" and are separated together with other products in the slag layer.

Thus, during HFC-heating of steels there appear many exothermic and endothermic reactions in mixtures containing boron carbide, borax, boric anhydride, calcium silicide and welding flux AN-348, at short-term high temperatures in limited volumes and on a limited surface. Taking into consideration that this type of heat treatment is a high-energy process in which power up to $260 \mathrm{~W} / \mathrm{m}$ can be introduced into the material, up to $30-40$ substances may be simultaneously the products of HFC-heating boriding.

\section{Results of Research}

To determine the practically feasible reactions of surface chemical (topochemical) boriding and the accompanying high-temperature processes, two sample mixtures were prepared, mixture 2, containing flux P-0.66 and boron carbide with $\%$ wt: $\mathrm{B}_{4} \mathrm{C}-84, \mathrm{P}-0.66-16$, an analogous mixture $2 *$ with added $20 \%$ wt of reduced iron powder PZh2M3 with a particle size of up to $0.315 \mathrm{~mm}$., and the thermal analysis was performed. The results of thermal analysis of sample mixtures in an inert atmosphere (Ar) are shown in fig 1. 


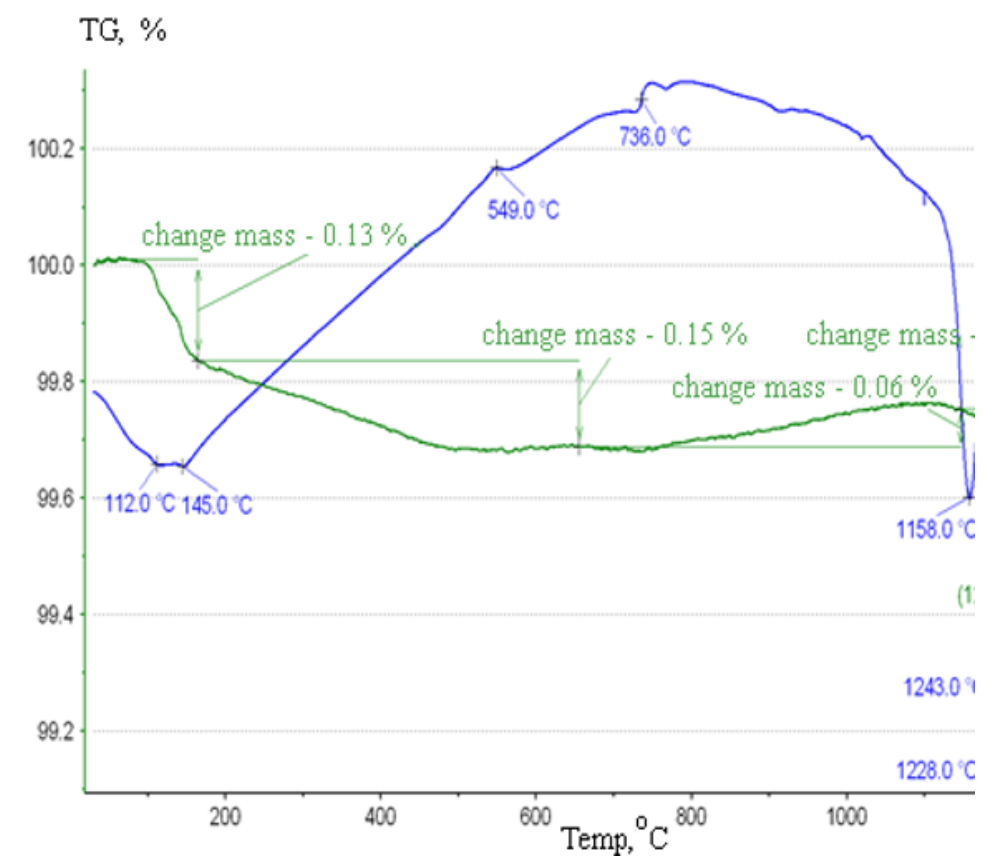

Fig. 1. Thermal image and results of differential scanning calorimetry for mixture 2 and mixture $2 *$ (weighed quantity $426 \times 5 \mathrm{mg}$ )

As it is shown in the figure 1, when heating sample mixtures in an inert atmosphere, the following reactions occur. When the mixture is heated up to $480-500^{\circ} \mathrm{C}$, crystallization water is separated, which is clearly seen on the TG curves, when the mixture loses from 0.15 to $0.37 \%$ of the mass.

As it is shown in the fig. 1 , starting from $480-500{ }^{\circ} \mathrm{C}$, noticeable mass loss or gain do not appear for all processes in sample mixtures. Effect and intensity of processes may be seen only in the DSC curve.

At a temperature of $549{ }^{\circ} \mathrm{C}$, a small exo-effect is observed in mixture 2, which is almost unnoticeable in the sample mixture $2^{*}$, it is shown only by the kink of the DSC curve and is associated with melting of one of the eutectics in the $\mathrm{B}_{2} \mathrm{O}_{3}-\mathrm{Na}_{2} \mathrm{~B}_{4} \mathrm{O}_{7}$ system. This is followed by a process of linear heating of the mixture, which at $731-736{ }^{\circ} \mathrm{C}$ in both mixtures is accompanied by the significant exo-effect of calcium silicide decomposing [8], for which products (in mixture 2) the endothermic processes start immediately, and in mixture $2^{*}$ endothermic processes start only at temperature higher than $860-870{ }^{\circ} \mathrm{C}$.

At $1010-1016^{\circ} \mathrm{C}$, a small $(0.07-0.1 \mathrm{~mW} / \mathrm{mg})$ endo-effect is observed in both sample mixtures, which we associate with melting and / or acid-base interaction of welding flux AN-348 components with the products of thermal dissociation $\mathrm{CaSi}_{2}$, borax or boric anhydride. Then, in mixture 2 , a series of significant endo-effects $(0.2-0.4 \mathrm{~mW} / \mathrm{mg})$ at 1158 ${ }^{\circ} \mathrm{C}, 1228{ }^{\circ} \mathrm{C}$ and $1243{ }^{\circ} \mathrm{C}$ appear, whose extended spikes disappear at $1263{ }^{\circ} \mathrm{C}$, associated with the formation of various borides, silicates and borates.

In contrast to the indicated endo-effects, the exo-effect is clearly seen in the mixture of $2^{*}$ at $1121^{\circ} \mathrm{C}$, which absolute value (taking into account the weighed quantity under study) exceeds the high-temperature endo-effects in mixture 2 by $4.5-10$ times, and is 2.0$2.5 \mathrm{~mW} / \mathrm{mg}$. This exothermic effect is associated with the primary boron-iron reaction.

When studying thermal images of mixtures 2 and $2 *$ obtained in air at a temperature elevation rate of $50-75^{\circ} \mathrm{C} / \mathrm{min}$ - in the mode that partially simulate and is realistic-like 
HFC-heating mode, there appeared many of the thermal processes occurring in an inert environment, as well as exo-spikes of secondary processes of oxidation of the mixture components, the metal surface and the reaction products.

When adding iron powder to the sample mixture $2 *$, a dual exo-spike was clearly seen on the thermogram, it corresponded to the formation of iron oxides $\mathrm{FeO}$ and $\mathrm{Fe}_{2} \mathrm{O}_{3}$ when it was oxidized with oxygen, the maxima of which were clearly identified by comparing the DTA and DTG curves at $598{ }^{\circ} \mathrm{C}$ and $690{ }^{\circ} \mathrm{C}$, which coincides with the literature sources' data [9]. Against the background of the exo-spikes of iron oxidation in the powder system $2^{*}$, the endo-peak of melting of the borate flux main system, beginning at $512{ }^{\circ} \mathrm{C}$, and ending at $540{ }^{\circ} \mathrm{C}$, is still clearly visible. The peak of thermal dissociation of $\mathrm{CaSi}_{2}$ also appears in system $2^{*}$, the phantom of which is noticed as a kink of the DTA curve at $718^{\circ}$ C.

Photos of samples were taken by means of OLYMPUS GX51 inverted metallographic microscope after etching of microsections, and response value of VDDS-5 eddy-current gage system was obtained as it moved above the sample surface.

Research results for the structure of coating obtained by SHS process during HFCheating of modified mixtures containing 20 and 30\% P-0.66 flux for $65 \mathrm{G}$ steel are shown in Figures 2-7.

As it can be seen at Figures 2-4, the structure of coating formed is one of the typical ones found earlier in boride coatings obtained from mixtures based on amorphous boron, the thickness of the resulting coating is $230-250 \mu \mathrm{m}$.

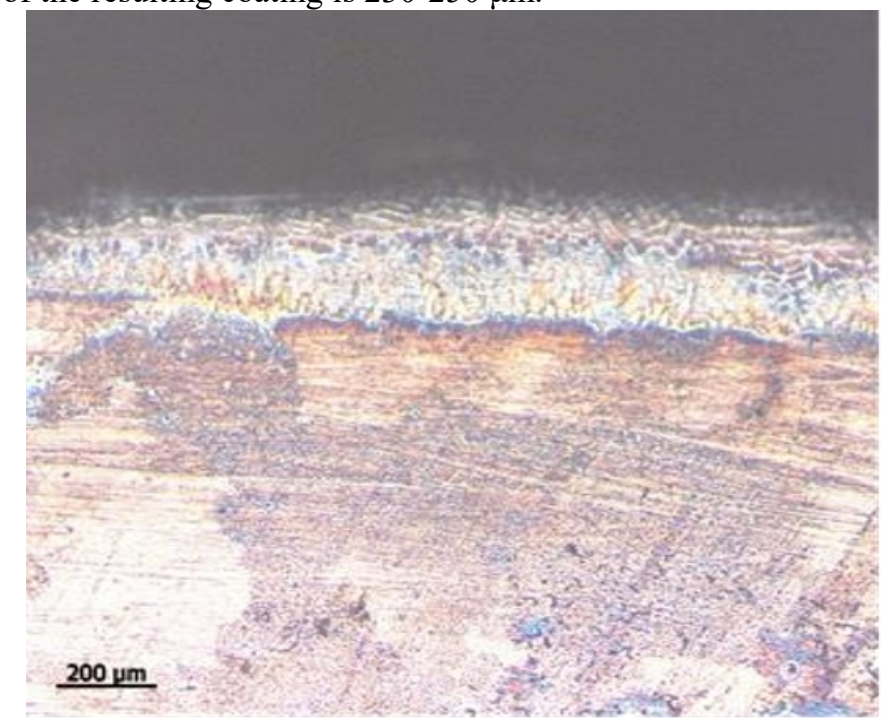

Fig. 2. Microstructure of coating received from modified mixture with $20 \%$ of P-0.66 flux (enlargement $\times 100)$. 


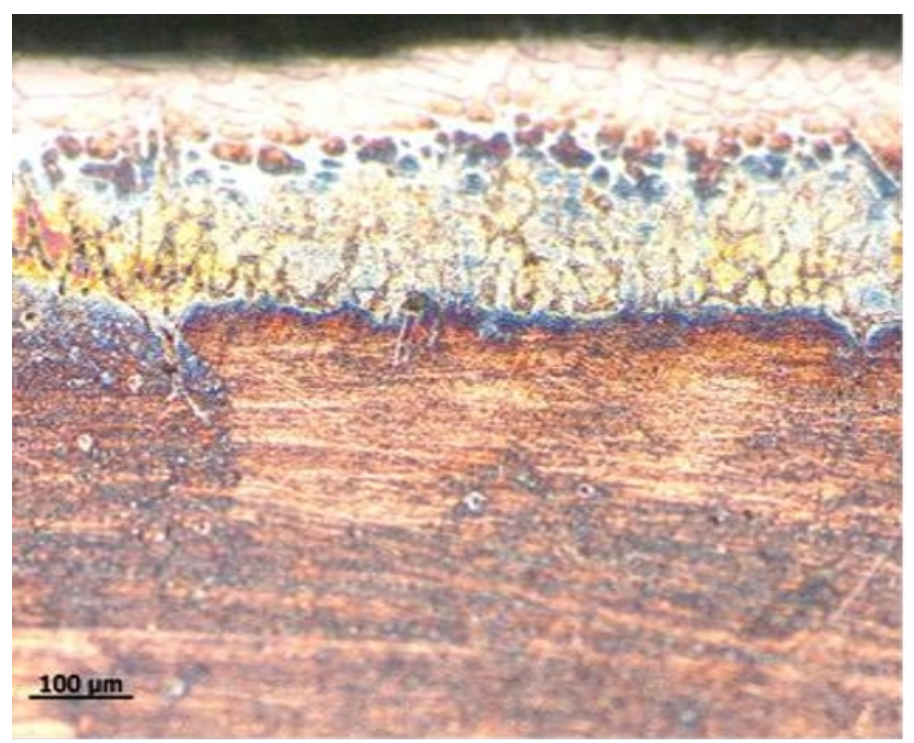

Fig. 3. Microstructure of coating received from modified mixture with $20 \%$ of P-0.66 flux (enlargement $\times 200$ ).

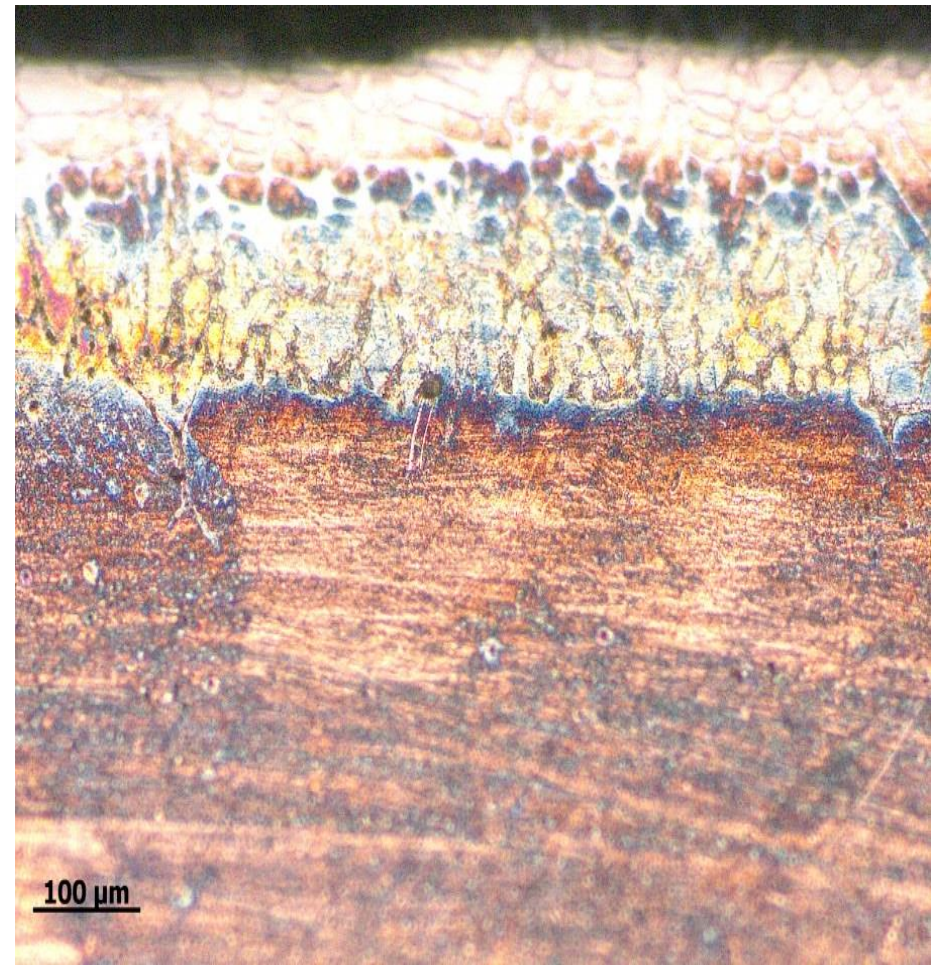

Fig. 4. Microstructure of coating received from modified mixture with $20 \%$ of $\mathrm{P}-0.66$ flux (enlargement $\times 500)$. 
As it can be seen at Figures 5-7, if content of P-0.66 flux increases, a similar structure of boride coating is formed in modified mixture, with marked boundary with base metal, but its thickness is smaller and amounts to $170-190 \mu \mathrm{m}$.

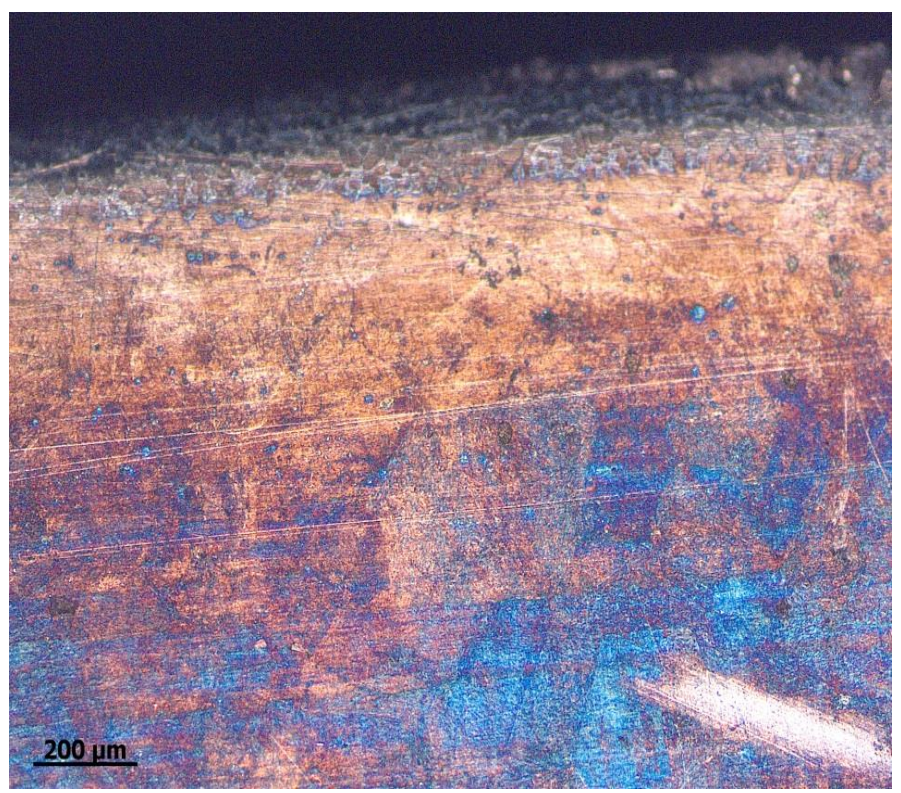

Fig. 5. Microstructure of coating received from modified mixture with $30 \%$ of P-0.66 flux (enlargement $\times 100)$.

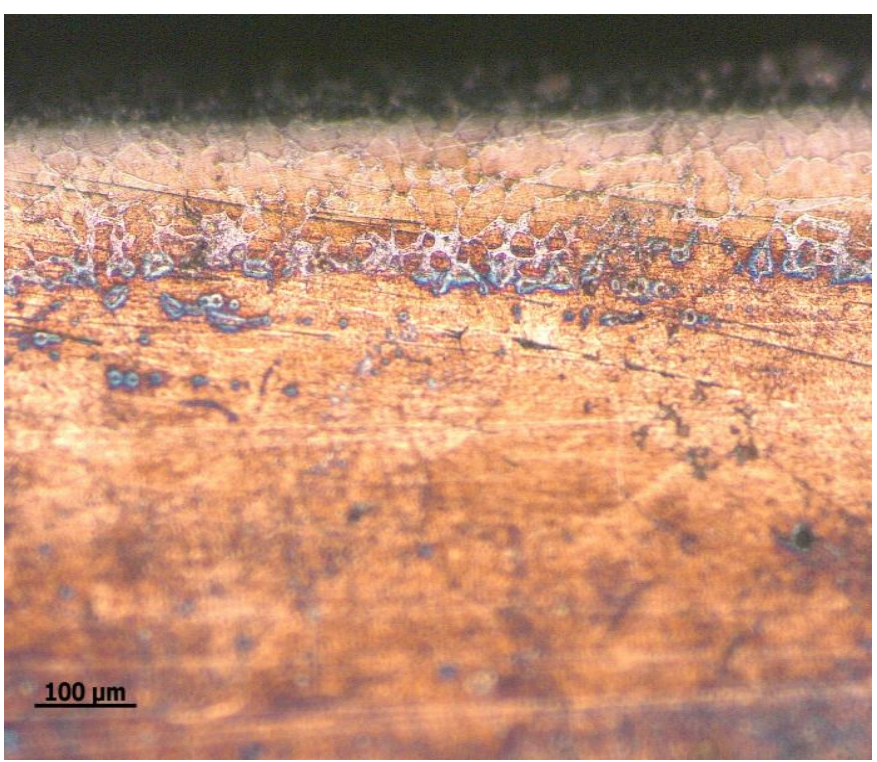

Fig. 6. Microstructure of coating received from modified mixture with $30 \%$ of P-0.66 flux (enlargement $\times 200$ ). 


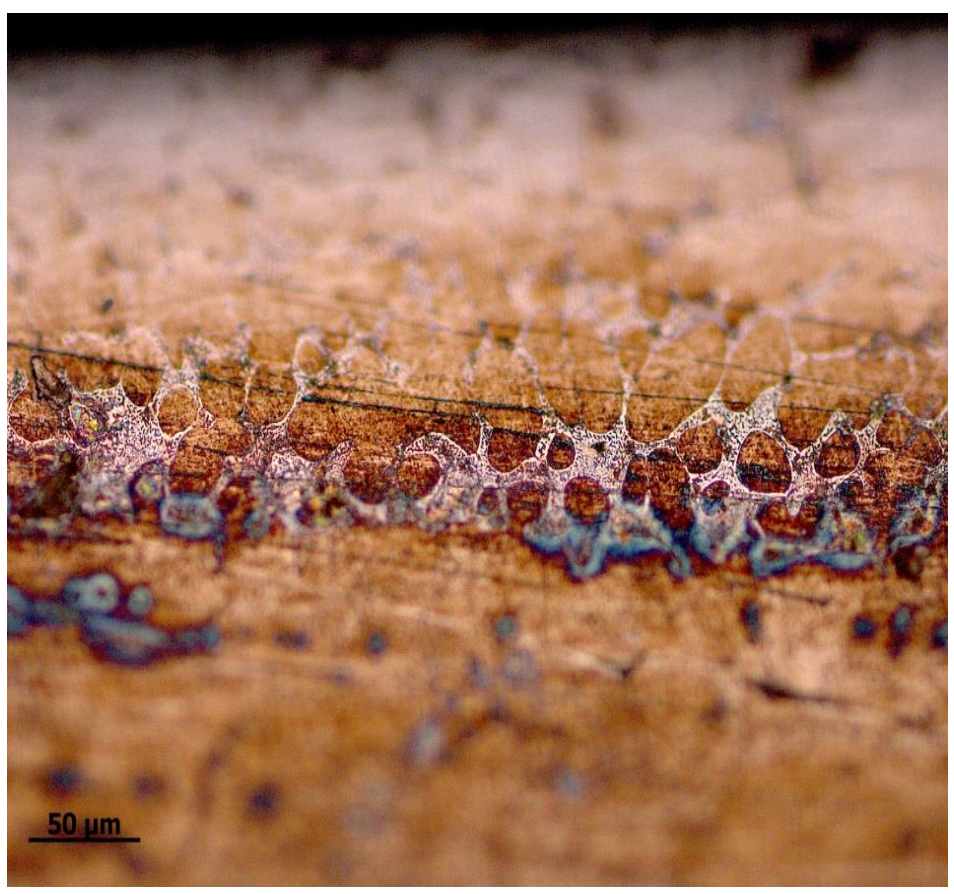

Fig. 7. Microstructure of coating received from modified mixture with $30 \%$ of P- 0.66 flux (enlargement $\times 500$ ).

\section{Conclusions}

Thus, the thermal study of boronizing mixtures showed, firstly, that all processes in the system at temperatures above $540-550{ }^{\circ} \mathrm{C}$ occur in the pseudo-liquid environment of the P0.66 borate flux melt, which already facilitates the boriding and delivery of active boron to the steel surface. Secondly, it confirmed the course of the reaction leading to the occurrence of reducing agents $\mathrm{Ca}, \mathrm{Si}$ and active boron in the boronizing mixture. Thirdly, it proved the fact that borides were obtained in the system by reactions of the type $2 \mathrm{Fe} 2 \mathrm{O} 3+8 \mathrm{~B}=4 \mathrm{FeB}$ $+2 \mathrm{~B} 2 \mathrm{O} 3$, as well as the direct interaction of simple substances.

Boride coatings obtained in both cases are two-phase composite materials. The darker, closed rounded areas are free of boron non-stoichiometric carbide phases of FexC composition (where $\mathrm{x}=1,2-2,5$ ), microhardness of which is $650-680 \mathrm{HV}$, the lighter separating net of their interlayer is Fe-B-C ledeburite-like iron-boride ternary eutectic, which microhardness reaches $850-920 \mathrm{HV}$. The hardness of the base metal is 400-450 HV. The difference in electrical conductivity fluctuations of the obtained coatings is determined.

\section{References}

1. Z. Silva, M. Ortiz-Dominguez, M. Keddam, Journal of Mining and Metallurgy, Section B-Metallurgy 50, 101-107 (2014).

2. E. Balikli, O. Yaman, Surface Engineering 27, 609-615 (2011).

3. S. Sen, U. Sen, C. Bindal, Surface \& Coatings Technology 191, 274-285 (2005). 
4. T.W. Spence, M.M. Makhlouf, Journal of Materials Processing Technology 168, 127-136 (2005).

5. M. Tabur, M. Izciler, F. Gul, I. Karacan, Wear 266, 1106-1112 (2009).

6. I. Uslu, H. Comert, M. Ipek, Materials and Design 28, 55-61 (2007).

7. O. Azouani, M. Keddam, O. Allaoui, Protection of Metals and Physical Chemistry of Surfaces 53(2), 306-311 (2017).

8. I. Campos-Silva, M. Ortiz-Domínguez, C. Tapia-Quintero, Journal of materials engineering and performance 21, 1714-1723 (2012).

9. W. Oliver, G. Pharr, Journal of Materials Research 7, 1564-1583 (2011).

10. J. Menčík, M.V. Swain, Journal of Materials Research 10, 1491-1501 (1995).

11. J. Menčík, Meccanica 42(1), 19-29 (2007).

12. O. Culha, M. Toparli, Journal of Materials Processing Technology 206, 231-240 (2008).

13. O. Culha, M. Toparli, Advances in Engineering Software 40(11), 1140-1147 (2009).

14. L. Campos-Silva, E. Hernández-Sánchez, Surface and Coatings Technology 206(7), 1816-1823 (2011).

15. V.I. Chernoivanov, V.P. Ljaljakin, V.F. Aulov, A.V. Ishkov, Journal of Friction and Wear 36(12), 132-137 (2015).

16. N.M. Mishustin, V.V. Ivanaiskii, A.V. Ishkov, Izv. Tomsk. Politekhn. Univ. 320, 6872 (2012). 